Research Article

\title{
The Socio-Economic Environment among Pastoral Communities in West Pokot and Turkana Counties in Kenya
}

\author{
Cornelius Sangura Wafula ${ }^{1}$, CrispinousoIteyo ${ }^{2}$, RuthoN.oSimiyu ${ }^{3}$ \\ ${ }^{123}$ Department of Peace and Conflict Studies, Masinde Muliro University of Science and Technology
}

\begin{abstract}
There are conflicts in many pastoral communities around the globe, while the Sahel region and EastoAfrica demonstrate sustained levels of inter-pastoral violent conflicts with associated potential impacts on their livelihoods. Turkana-Pokot Violence across borders, conflict is now the norm. A number of efforts have been made by various bodies to bring peace to the region. Despite the Kenya Police Reservists' disarmament and arming communities, peace building meetings, prosecuting perpetrators, declaring illicit firearms surrender amnesties, and setting up peace committees continue to prevail in the region, insecurity and violent conflict. This study was primarily utilized the Protracted Social Conflicts (PSC) theory of Edward Azar. The study adopted descriptive research design. The study was conducted in Turkana and West Pokot Counties of Kenya. A total of 434 respondents were targeted in Pokot North and Turkana South. The sample size of 130 respondents was selected from each of the two Sub Counties. Data was collected using questionnaires, interview schedules, and document analysis and focus group discussions. Pilot study was conducted in Wajir County to establish reliability and validity of research instruments using content analysis and Cronbach alpha respectively. Quantitative data was analyzed using the SPSS to obtain descriptive statistics and chi-square. Qualitative data was analyzed by use of themes and presented in narrative form. Quantitative data was presented in form of tables, charts and graphs. Qualitative data was presented in form of narratives and verbatim quotations. The findings of the study revealed that, the proximity of Turkana County to three international borders, namely; Uganda, South Sudan and Ethiopia had contributed to the proliferation of small arms through the porous borders that are not governed by the respective governments. This contributed to the availability and cheapness of small arms in Turkana County as a whole, hence the sustenance of the conflict between the two communities. Therefore, this theoretical framework was useful in anchoring the study. The study findings therefore suggested that politics, governance, peace building strategies, commercialization of raided animals and proliferation of small arms are the sustainers of conflict among the pastoral communities of Turkana and West Pokot Counties of Kenya. The next chapter presents the effectiveness of the existing conflict management system towards the conflict between the Turkana and Pokot communities.
\end{abstract}

\section{Key Words: Conflicts, Cattle raids, Ethnography, Competition for resources, Pastoralism, ASALs}

\subsection{Introducation}

Conflict is a symptom of social inequity and uneven power sharing. When they follow contradictory aims, it is a condition of at least two recognizable classes in conscious contrast to each other. In several regions of the world, disputes are prevalent phenomena, especially in dry lands, which are blessed with limited natural resources. Combined with population growth, rapid environmental change has contributed to an unprecedented need for energy. Competition for ownership of and access to the meager capital that in turn cause tensions were the implications. Environmental shifts linked to nature have been shown to be among the primary sources of disputes (Mathew et al., 2009; The Greater Horn of Africa (GHA) climate change has been shown to raise the incidence of droughts from one in six years to one in three years. For example, in Ethiopia, the occurrence of drought has risen from 6-8 years to the current 1-2 years (Meier et al., 2007). 
In almost 21 countries throughout the African continent, pastoralists inhabit (Schilling, Opiyo and Scheffran, 2012). Pastoralism is a big technique for economic development in which people collect livestock populations, primarily in arid and semi-arid lands (ASALs). ASALs occupy about 80 percent of the landmass of Kenya and sustain about a third of the human population of the world and 70 percent of the national herd of livestock. Kenya's ASALs account for an approximate 13 million pigs, 25 million goats, 14.9 million horses, 1.7 million donkeys and 2.9 million camels (KNBS, 2010). Pastoralism in Kenya contributes about $12 \%$ to the gross domestic product of the country (FAO 2005), with the livestock sector generating an approximate $90 \%$ of all job prospects and more than $95 \%$ of ASALs' household income (Kiambe \& Guliye, 2011).

Pastoralism, according to Azarya (1996), refers to an economy focused on livestock raising that may be undertaken by sedentary or nomadic communities. Many who receive part of their living from livestock and livestock items involve pastoralists. They involve many who are still tied to the pastoral tradition, even though the key source of income for livestock is not (Humanitarian policy group, 2009). Pastoralism is more than just a method of development in all its ways. A certain form of social organisation and cultural patterns and behaviors are concerned (Markakis, 2004). In the other hand, nomadism applies to the degree of pastoralist spatial movement; therefore, pastoral development is conceptually separate from the extent of residential mobility.

In pastoral livelihoods, livestock ownership performs numerous social, economic and religious functions, such as supplying household members with a daily supply of food in the form of milk, meat and blood, cash income to compensate for cereals, schooling, health care, and other facilities. In pastoral cultures, livestock is also important for the payment of dowry, reimbursement during raids for wounded persons, indicators of stability and honor, stockpiling of wealth and protection against famine, disease and other disasters. In addition to acting as a means of development, storage, transport and transition of food and resources, livestock is thus a fundamental type of pastoral capital (Behnke, 2008).

The disputes are primarily about livestock and associated productive properties, namely water, land and pasture, as pastoralism revolves around livestock. Such tools directly relate disputes to the harassment and stealing of animals, known as raiding, which are both a contributing factor and an articulation of dispute. Mwangi (2006) claims that raiding contributes to mistrust within communities that is a precursor for war, and this claim seems to be reinforced by Schilling et al (2012) by explaining that communities use raiding to communicate their animosity to enemy communities.

Eaton (2008) and Schilling et al (2012) notice the difficulty and frequency of the Turkana and Pokot pastoral boundary disputes. The frequency has moved from competitiveness for limited capital, racial or group hostility, insufficient fulfillment of human needs, divide and rule imperial policies, to conflict entrepreneurs gaining from conflicts, and weak governance (Juma \& Simiyu, 2019). Semi-arid and arid lands in Kenya make up 439,000 km2 of land mass, which is equal to $80 \%$ of the overall land mass of Kenya. Gray (2000) points out that there is a strong correlation in Karamoja between shifting circumstances internationally, natural capital, livelihoods, poverty, and violence. The supply of services has been adversely influenced by volatile weather conditions and prolonged droughts.

Frequent crop failures have contributed to food shortages in the area, and this has resulted in increased outbreaks of raids and increased rivalry for water and pasture, according to a study by IGAD CEWARN (2004). Droughts have also lead to livestock destruction, fostering raids and counter raids. This claim is backed by Schilling et al (2012) who reported that starvation and drought triggered the Turkana raid while the Pokot raid charged bride price and wealth accumulation.

Traditionally, pastoralist societies in East Africa have been founded on nomadic populations, migrating in search of land to graze together with their respective herds. The increased migration of citizens southwards during African history is mostly attributed to pastoral societies (Iliffe, 1995). It is remembered that pastoral 
warfare and livestock rustling have acted primarily as a means for the expansion of capital and territory by these cultures on several occasions. Institutions have also been set in motion to inflict mass abuse.

Many African scholars identified it as the cause of those recurring conflicts (Murunga \& Nasong'o, 2007; Kanyinga, 2009, the colonial administration has driven these ethnic groups out of their historical homelands to allow land for farming. These groups are now clamoring for fresh territories in unusual lands, where they have long been at war with the prior settlers. Indeed, the Turkana and Pokot Communities were adapted to certain colonial policies by adopting 'pastoral transhumance' in which they usually forsaken nomadic life but conserved nomadic herding (Kenya Human Rights Commission, 2010). This change brought the battlefields into the grasslands on which the livestock were padded by the citizens themselves.

Different views have described the academic discussions on the drivers of disputes. The leading viewpoint is the school of thinking of reasonable choice or war economics, which is focused on econometric involvement in the 'greed verses grievance' debate on the origin of conflicts (Juma et al., 2018). In the 1990s, some dispute and spirited debates among scholars were created by the new political economy of confrontation. The position was that economic consideration frequently affects the calculations and actions of the parties to a dispute, giving birth to a specific conflict economy (Balletine \& Sherman, 2007).

The key sources of tension in a community are the generators of conflict. In Kenya, a variety of studies have looked at different aspects as generators of conflict. In several of them, two things are apparent. First, but largely indirect, both studies find a link between environment variables and the incidence of crime. Second, it is possible to distinguish two kinds of research: data-based studies performed at the national level and observational studies with a local emphasis.

Sustainers of wars intensify tension and prolong current levels of conflict as well as minimize the prospects of stability. Conflicts are primarily sustained where parties do not pledge themselves credibly to mutually advantageous arrangements that they can achieve (Weingast, 1995). In other terms, at least one party will not efficiently convince the other that at any future date it will not renege on a deal and manipulate it. Since exploitation may be quite expensive - including the coordinated killing of one party by another-groups can tend to bear even high war costs today to prevent tomorrow's exploitation.

Both Turkana and Pokot are pastoralists residing in the extreme North Rift zone with ancient disputes and conflicts over cattle, pasture and prolonged armed ethnic dispute (McCabe, 2004). This region is marked by high levels of poverty and illiteracy, according to Mwaniki et al (2007), with life expectancy varying from 57 years among the Turkanas to 66 among the Pokot. In addition, Mwaniki et al (2007; Goldsmith, Ahmed and Babiker 2007; Greiner, 2013) claim that among these groups, cattle rustling carries a histo-cultural face, noting that the practice has been commercialized since 1992.

Schilling et al (2012) appear to accept this claim and explain that the growth of commercialization of raided livestock further enhances the willingness of raiders to participate in conflict/small raids. Commercialization is described by Kratli and Swift (2003) as 'an element of the wider integration of pastoralists into a market economy.' Commercialized raiding is encouraged by increased consumer access, increasing meat demand as part of high urban population growth and improved road connectivity hitting pastoral regions (Juma et al., 2018). This method of raiding is carried out with the express purpose of selling cattle for immediate benefit rather than replenishing own herds (Mkutu 2010). This has encouraged the persistent and constant rivalry between the Turkana and Pokot to be raided.

Porous boundaries, Turkana County's immense scale and the reality that it shares borders with three nations exposes people to a number of conflicts (ITDG-EA \&AU-IBAR, 2003; Goldsmith et al., 2007). The Turkana are in competition with Ethiopia's Merille and Nyangatom, Sudan's Toposa and Dodoth, and some Ugandan Karimojong tribes. This is attributed to the proximity of Turkana to the long, distant and porous foreign boundaries. The western boundary of Kenya with Uganda, which stretches from Busia in the south to Turkana in the north, has a total of $933 \mathrm{~km}$ and just three formal crossing points. 
Pastoralists typically cross from one side to the other, while straddling the boundary often (Mkutu, 2007). Because of its remoteness and weak connectivity, which limits foreign investment, Turkana is a problem for administration (Mkutu \& Wandera, 2013). Turkana was classified as the poorest county in a recent government study, with 94.3 percent of residents living in poverty, while 92 percent of Pokot live in poverty (Omari, 2011). In the national strategy, pastoral concerns are not properly expressed and no conflict management policy is in effect (Mkutu, 2009), while good customary governance institutions remain (Knighton, 2003; Kenya, 2010).

In a vicious cycle of armed violence that has taken lives and ruined property of uncertain significance over a long period of time, the Pokot and Turkana groups have become perpetrators and victims in equal measure. The violent struggle between these groups has been traced to the proliferation of small arms and light guns, political incitement, rivalry for water and pastures that are scarce and dwindling, the celebration of a culture of heroism that increases the social standing of raiders, the deterioration of the position of community leaders, the marginalization of successive governments and the lack of state protection.

Violent violence can be seen in a cycle of revenge killings and cattle raids among these three groups, sometimes beginning with morans from one group raiding a rival community either to replenish stock or to feed the highly lucrative cattle market that is thriving in and outside the Rift Valley area., this spirals into attacks and counter-attacks that escalate to lengthy stretches of aggression after a while Juma \& Simiyu, 2019). As a consequence of inaction by the government of Kenya, violent violence between these groups can also be observed.

A main feature of the state is the provision of appropriate protection that safeguards human life and property, these groups have never appreciated being part of the Kenyan state, the state has always had little involvement in pastoralist-occupied arid and semi-arid lands. The 1965 Sessional Paper No 10 (GoK, 1965) prioritized Kenya's economic development in "strong opportunity" areas such as the White Highlands and other infrastructure areas, thereby setting the framework for the marginalization of Kenya's pastoralist populations.

Several massacres punctuate the trajectory of violent conflict among pastoralist communities in Kenya. Several methods to dispute settlement and peace building have been adopted, ranging from robust disarmament by both the colonial and subsequent autonomous Kenyan regimes to the use of traditional authority to the signing of peace deals with sanctions between separate groups for each individual who breaks the peace. The absence of a government has also contributed to the provision of critical social services by non-governmental organisations and, with mixed outcomes, are also engaged in numerous conflict resolution efforts.

The creation of peace, identified as any action carried out in order to deter, mitigate or settle disputes, is a regular practice among warring populations. Lind (2006) states that donor agency operations concentrate on conflict resolution and peace-building activities, especially in the pastoral areas of Eastern Ethiopia, Northern Kenya, Southeastern Sudan and Northern Uganda.

For instance, conflicts about missing crops and connections to water and pastoral routes are held at local levels by the Council of Elders (UNDP Sudan) (2010). Various local and foreign non-governmental organisations (NGOs) are participating in peace building at the state level. The Development Initiative Connection Connect (DIAL) Africa in Somalia (DIAL, 2012), the Greater Horn of Africa Initiative (GHAI) for the Greater Horn of Africa (GHA) (USAID/REDSO, 2003) and the Netherlands, the Canadian International Development Agency (CIDA) and the United Nations Development Program (UNDP), which initiated a project to mitigate resource-based disputes in Sudan in 2004 (United Nations Development Programme Sudan, 2010).

In the two communities, peace work has been described as maintaining violence and is now a major business along the frontier between Kenya and Uganda. Mkutu (2016) provides an account of how peace meetings in 
the North Split have been just as much a part of the lives of citizens as the incessant raids on cattle. Many NGOs rely on peace talks that are shown to have little specific effect and often create much more friction and abuse (Eaton 2008). Because of rivalry for resources between the multiple organizations, their interventions lack continuity, teamwork, and networking (IGAD-CEWARN, 2004; USAID FEWS NET, 2005). More pragmatically, the organisations behind these meetings have recognized that while insecurity persists, their service objectives are difficult to accomplish (Eaton, 2008).

The invention of 'gun power' has seen the country progress selectively on the new gun variety on the market and, sadly, often access to more sophisticated guns comparable to those carried by state security forces, which can characteristically have and monopolize all instruments of force and aggression in its field of jurisdiction (Mkutu \& Wandera, 2017). The evolving essence of cattle rustling has been stressed by scientists since the 1990s (Hendrickson, Armon \& Mearns, 2008) and attempts to justify this argument to the increased availability of specialized automatic weapons such as AK 47 (McCabe 2004; Mkutu, 2016). In a report on these conflicts, these evolving dimensions and patterns required this researcher to discover the socio-economic causes of the war, the local players that perpetuate it, and the potential explanations why the government and other peace actors have struggled to mitigate this conflict by peace initiatives.

One of the oldest disputes in northern Kenya is the Turkana dispute in the north of East Pokot (McCabe, 2004). When Turkana attempted to invade part of the Pokot country, a new wave of confrontation erupted in 1995. (Bollig \& Osterle, 2007). The past two years. Since then, the war has more and more publicly been a territorial dispute involving almost constant joint killings (from both sides) and large-scale displacements in 2012. (Andae \& Bii, 2012). Schilling et al (2012) also reveals that for so many decades, the Turkana and Pokot ethnic groups have been on a fighting road that they cannot remember a year when they went without raiding and confrontation. In recent years, the rivalry has intensified. This statement is in line with other studies that have documented increased violence in north-western Kenya between the Turkana and the Pokot and other groups (McCabe, 2004; de Vries, Leslie and McCabe, 2006; Omolo, 2010; UNDP 2011). In 2013, in the month of March just before elections, the Turkana and the Pokot clashed at Lokapel in Katilu in Turkana south due to a boundary dispute. All these explanations and the continued escalation and frequency of violence were a justification for the researcher to include the year 2013 in this study.

\subsection{Theoritical Framework}

This study was primarily utilized the Protracted Social Conflict (PSC) theory of Edward Azar (1990) as clarified by Ramsbotham (2005) and the theory of peace building as postulated by Lederach (2005). This is because it seeks to understand the socioeconomic origins of disputes at the local level and the breakdown of government that then triggers protracted and destructive conflicts. One of the first analytical efforts to comprehensively examine and clarify the protracted existence of intra-state disputes is made by Edward Azar (Ramsbotham, 2005).

"Influenced by the ongoing conflicts in Lebanon, Azar established and defined a structure for the study of such conflicts as the Protracted Social Conflict (PSC) as: "the protracted and sometimes violent struggle of communal groups for basic needs such as protection, acceptance of security, recognition of social conflicts (Azar, 1990). Azar claimed that incidents of prolonged collective brutality were initiated by the deprivation of essential human needs to a substantial section of the community. There are four pre-conditions isolated as prevalent PSC origins by Azar. These are: social material, lack of basic needs, government and the position of the state, and foreign connections (Azar, 1990).

Given the fact that this kind of dispute is demonstrated by Turkana and Pokot, the PSC theory of Azar is important here. The PSC varies from the theory of Kenneth Waltz (1959), whichogives the distinctions between device, state, and individual. The Turkana and Pokot demonstrated the kind of Azar's PSC dispute based on the research results as revealed by the study, and therefore the theory was applicable to this study. This significance was evident in the related reviewed literature that showed how pastoralists suffer from changes in environmental conditions that exacerbate raids, changes in livelihoods, and change in the cultural 
nature of raids too commercialization, change in the intensity and frequency of conflict due too raiding patterns, impact on the conflict of the proliferation of small arms, failure to build peace

The data checked also revealed the correlation between the theory (PSC) and the causes and effects over time of the dispute under analysis. Azar (1990) describes that communal groups' protracted and sometimes violent fight for basic needs such as stability, acknowledgement and approval, equal access to political institutions and economic participation has contributed to agitation among the groups affected. This theory resonates with why, as was stated by respondents from both sides, the pastoralists battle each other.

In order to fulfill their safety needs, the literature studied shows the communal material where the pastoralists groups depend on their warriors to defend and recognize their societies from external violence. The two groups recognized their fighters as defenders of their interests, battling for their acknowledgement, filling the government's void. The two parties both understood that aggravating aggression was courageous and willing to protect the society. These people were kept high up in the society and often voted to serve the population in the National Parliament during the general elections while meeting their demands for electoral acceptance. Hence, the PSC was important to this analysis.

Protracted Theory of Social Dispute is important to the thesis as conflict between pastoralist groups is related to underlying pre-conditions that have been in place for years. The theory was therefore instrumental in extending the study's first goal, which sought to ascertain the existence and scale of socio-economic factors among the pastoral communities of Kenya's West Pokot and Turkana Counties.

The theory clarified the social origins of disputes and local level lack of government, which then triggers protracted and violent conflicts. The theory denotes violent relations between communal groups focused on deep-seated racial, national, religious and cultural hatreds that continue with occasional bursts of violence over long periods of time; intractable confrontation is almost unavoidable when the existence of a community is challenged or irritated.

Deep-seated cleavages based on racial, religious, cultural or ethnic lineages are faced by pastoralist groups. These cleavages are defined by continued animosity to occasional incidents of violence; and by the dissatisfaction of the desire for security,recognition and distributive justice for human beings. Provided that this kind of confrontation is demonstrated by pastoralist groups, Azar's PSC and Lederachs, theories of peace building are important here.

The PSC and peace building theories of Azar are important to this analysis as the related literature examined indicates that pastoralists suffer from changes in ecological conditions that intensify raids, livelihoods, cultural nature of commercialization raids, the severity and frequency of conflict due to raids, the effect of small arms on the conflict, the lack of modalities for peace building to curb conflicts, Bad governance and the effect of politics on the confrontation that has inevitably been prolonged and maintained conflicts.

\subsection{Methodology}

The study adopted descriptive research design. The study was conducted in Turkana and West Pokot Counties of Kenya. A total of 434 respondents were targeted in Pokot North and Turkana South. The sample size of 130 respondents was selected from each of the two Sub Counties. This number was broken down as follows; 6 deputy county commissioners, 12 sub county criminal investigation officers, 2 county commissioners, 2 women representatives, 18 chiefs, 34 assistant chiefs and 56 village elders. Data was collected using questionnaires, interview schedules, and document analysis and focus group discussions. Pilot study was conducted in Wajir County to establish reliability and validity of research instruments using content analysis and Cronbach alpha respectively. Quantitative data was analyzed using the SPSS to obtain descriptive statistics and chi-square. Qualitative data was analyzed by use of themes and presented in narrative form. Quantitative data was presented in form of tables, charts and graphs. Qualitative data was presented in form of narratives and verbatim quotations

\subsection{Findings}




\subsection{Introduction}

The findings of the study reflect on the reality of socio-economic factors that have made the pastoralist conflict between the Turkana and Pokot to be protracted as undertaken by this research between the years 2003 and 2016. The researcher in this section identified and discussed the socio-economic factors that have influenced peace building in Turkana South (Kainuk region) and Pokot North (Alale region). The study focused on the nature and extent of socio-economic factors among the pastoral communities of WestoPokot and Turkana Counties in Kenya. It assessed the effectiveness of the existing conflict management strategies among the pastoral communities of West Pokot and Turkana Counties in Kenya and lastly interrogated the strategic options of peace building and sustainable peace among the pastoral communities in West Pokot and Turkana Counties in Kenya. The findings of the study were based on the following thematic areas.

\subsection{Socio-Economic Factors}

The study determined the socio-economic factors among the pastoral communities in Turkana and Pokot Counties under the following themes;

\subsubsection{Climatic conditions}

The study sought to determine whether there was a link between the erratic climatic conditions and conflict among the turkana and pokot communities of Kenya. To answer this theme the respondents to respondent to the following statements as indicated on a likert scale of of SA = Strongly Agree, $\mathbf{A}=$ Agree, $\mathbf{U}=$ Undecided $\mathbf{D}=$ Disagree and $\mathbf{S D}=$ Strongly Disagree. In this study descriptive statistics and chi-square was used in data presentation as indicated by fo for observed frequency and fe for the expected frequencies in computation of chi-square values. Table 4.1 shows the study findings.

Table 4. 1: Climatic Conditions and Conflict among Turkana and Pokot Communities of Kenya

\begin{tabular}{|c|c|c|c|c|c|c|c|c|}
\hline \multirow[t]{2}{*}{ Climatic conditions } & \multicolumn{2}{|c|}{$\begin{array}{l}\text { Strongly } \\
\text { Agree }\end{array}$} & \multicolumn{2}{|l|}{ Agree } & \multicolumn{2}{|c|}{ Disagree } & \multicolumn{2}{|c|}{ Total } \\
\hline & Fo \& \% & $\mathrm{Fe}$ & $\begin{array}{l}\text { Fo \& } \\
\%\end{array}$ & $\mathrm{Fe}$ & Fo \& \% & $\mathrm{Fe}$ & $\mathrm{N}$ & $X^{2}$ \\
\hline Pokot & $\begin{array}{l}30 \\
(45 \%)\end{array}$ & 27 & $\begin{array}{l}32 \\
(49 \%)\end{array}$ & 33 & $3(6 \%)$ & 4 & 65 & .88 \\
\hline Turkana & $\begin{array}{l}25 \\
(38 \%)\end{array}$ & 27 & $\begin{array}{l}35 \\
(54 \%)\end{array}$ & 33 & $5(8 \%)$ & 4 & 65 & .61 \\
\hline Total & & & & & & & 130 & 1.49 \\
\hline
\end{tabular}

\section{Source: Field Data 2017}

As portrayed from Table 4.1, the results of the study questionnaires indicateothat there was no significant difference between climatic conditions and conflict among the Pokot and Turkana communities in Kenya $\left[\chi^{2}\right.$ $(2, N=130)=1.488, p<.05]$; the difference between observed and expected values under the null hypothesis were very consistent and therefore a smaller discrepancy resulted in a smaller value for chi-square which was lower as compared to the table $\chi^{2}$ of 5.99. Thus data did fit the null hypothesis and the hypothesis was retained in favour of the alternative hypothesis because there was no statistically significance difference between climatic conditions and conflict between the two communities. However climatic changes were more likely to lead the Turkana community into conflict with the Pokot as shown by the calculated $\chi^{2}$ of 0.608 among the Turkana and $\chi^{2}$ of 0.88 among the Pokot respectively. The supply of resources has also been adversely influenced by volatile weather conditions and prolonged droughts. Frequent crop failures in the area also contributed to food insecurity (Schilling et al., 2012). The researcher (2019) claimed this to have culminated in increased cattle raid accidents, and increased rivalry for water and pasture, and droughts have contributed to animal destruction, fostering raids and counter raids. The lack of economic activity 
offers an incentive for raids, which is an economic activity for some individuals over time. The results align with other observations obtained from focus group meetings in the research region with village elders. The value of livestock and natural resources as important elements of the dispute between the Turkana and the Pokot is confirmed by Schilling et al (2012).

For separate motives, Turkana and Pokot are involved in the same dispute. Most raiders do so in Turkana because of starvation and drought as their primary and secondary factors for participating in livestock raiding. Greiner (2013) suggests that the lack of pasture and water is marked by pastoral areas and that the battle over temporary access to these services contributes to violence. This literature connects sustained adverse climatic shifts to prolonged raids between these two societies and violent confrontation. This research therefore aimed to establish whether the ongoing violent conflict between Turkana and Pokot was responsible for deteriorating ecological/climate conditions.

A FGD composed of 23 village elders in Kainuk narrated to the researcher how the drought of "napei kopo" (drought of one tin), which referred to the amount of maize each person got from relief agency ration, lasted longer than expected. The chief of Lomut location asserted that;

During that drought the Turkana lost almost all the livestock they had and had to move to town centers where they congregated in camps where they could be reached easily by the relief agencies. Here they got food, water and medication as they recovered from the ravages of famine and drought.

Source: Field Data (2017)

The explanation given refers to the drought of 2013 in Turkana. The results also revealed that Pokot North respondents thought that the origin of the dispute and its survival is responsible for climate change. According to Kaptutin location nyumba kumi peace initiative coordinator,

The people of Pokot North said they hadn't been as hungry as Turkana, but they had to endure severe droughts like the one of 1999-2002 at certain periods. Source: Field Data (2017)

From a FGD with a group comprising 8 village elders in Kacheliba, Kongelai, Chepararia and Chesogon, one village elder asserted that;

In the past, extreme droughts had led them in Karamoja, Uganda to look for fruit, water and pastures. Often they challenged pastoralists in this region because of the country's strict laws. But they mainly relocated their animals to the Turkana frontier, where they were faced with various aggressions. After the drought, people often travel home to strategize how to raid Turkana, understanding the roads well and precisely where the livestock can be reached quickly. Source: Field Data 2017

The results from the questionnaires, interview schedules and FGD are compatible with earlier IGAD CEWARN (2004) findings, which stated that there was a clear correlation in Karamoja between globally shifting climate factors, natural resources, instability of livelihoods and violence. The supply of services has been adversely influenced by volatile weather conditions and prolonged droughts. In the area, repeated crop failures have contributed to food insecurity. This is considered to have contributed to increased cattle raid accidents, and increased rivalry for water and pasture, and droughts have led to livestock destruction, promoting raids and counter raids. Most raiders do so in Turkana because of starvation and drought as their primary and secondary factors for participating in livestock raiding.

Greiner (2013) suggests that the lack of pasture and water is marked by pastoral areas and that the battle over temporary access to these services contributes to violence. According to Mwaniki (2007), he was of the 
opinion that the absence of socio-economic operations presented an impetus for raids that have become an economic practice for some individuals over time, confirming the value of livestock and natural resources as important elements of the Turkana-Pokot dispute. For separate motives, Turkana and Pokot are involved in the same dispute.

The inhabitants of both regions demonstrated to the researcher that after catastrophic droughts, populations still tried to rebound and that they were more likely to raid communities with which they had sour partnerships or those who were vulnerable in terms of self-defense in comparison to the power of arms. One respondent at Konyao in Pokot North, from FGD, said that;

Such results might be expected but much of the state apparatus will hesitate before the damage was achieved instead of constructive. The local community often considered it to be neglect and an indication of disenfranchisement since predictable results are more likely than pastoralism in other agricultural sectors to draw attention.

\section{Source: Field Data (2017)}

A village elder in a FGD in Kainuk recorded that there was a pattern in the region where the weather conditions intensified to the point that for at least two to three years there was no rain. The group endured drought and starvation for prolonged stretches at those times. In pursuit of water and grass, much of the livestock will be transferred to the wetter areas of Pokot North and Moroto in Uganda. They will come into touch with the host culture there, who would not be accommodating under some situations. Clashes would arise and further cattle would be lost to the Turkana population. The Turkana people will be destroyed by drought and starvation back home, and would encounter brutality in the territory of the enemy at the same period. Furthermore, the village elder complained that often they felt that the gods appeared to neglect them. For the next ten years, this cycle of drought and starvation will replicate itself until environmental patterns would adjust for improved conditions.

\subsubsection{Livelihood Factors}

The study sought to determine whether there was a link between changing livelihood patterns of the Turkana and Pokot pastoralists and the continued conflict that had escalated for years between them. To answer this theme the questionnaires were used to capture data from respondents based on the levels of their agreement with set statements as indicated on a likert scale of of SA $=$ Strongly Agree, $\mathbf{A}=$ Agree, $\mathbf{U}=$ Undecided $\mathbf{D}=$ Disagree and SD = Strongly Disagree. In this study observed frequency (fo) and expected frequencies (fe) were used to compute the chi-square statistics that was used to interpret the study findings. Although Butler and Gates (2012:) see demographic distress, climate change and resource shortages as the basic motors of inter-ethnic abuse, these claims have been refuted by several empirically validated studies arguing that structures and political calculations are decisive in steering the responses of citizens either to confrontation or cooperation to these causes. This thesis analyzed the forces of survival that formed the rivalry between these two groups. Table 4.2 indicates the results from the analysis.

Table 4. 2: Livelihood Factors and Conflict among Turkana and Pokot Communities of Kenya

\begin{tabular}{|c|c|c|c|c|c|c|c|c|}
\hline \multirow[t]{2}{*}{ Livelihood Factors } & \multicolumn{2}{|l|}{$\begin{array}{l}\text { Strongly } \\
\text { Agree }\end{array}$} & \multicolumn{2}{|l|}{ Agree } & \multicolumn{2}{|l|}{ Disagree } & \multicolumn{2}{|c|}{ Total } \\
\hline & Fo \& \% & $\mathrm{Fe}$ & $\begin{array}{l}\text { Fo \& } \\
\%\end{array}$ & $\mathrm{Fe}$ & Fo \& \% & $\mathrm{Fe}$ & $\mathrm{N}$ & $X^{2}$ \\
\hline Pokot & $\begin{array}{l}31 \\
(48 \%)\end{array}$ & 30 & $\begin{array}{l}30 \\
(46 \%)\end{array}$ & 30 & $4(6 \%)$ & 4 & 65 & .033 \\
\hline Turkana & $\begin{array}{l}29 \\
(45 \%)\end{array}$ & 30 & $\begin{array}{l}31 \\
(48 \%)\end{array}$ & 30 & $5(7 \%)$ & 4 & 65 & .099 \\
\hline
\end{tabular}




\section{Source: Field Data (2017)}

$$
\chi^{2}(2, N=130)=0.132, p<.05
$$

As portrayed in Table 4.2 the inferential statistics from the questionnaires showed that the calculated $\chi^{2}$ value of 0.132 was lower than the critical $\chi^{2}$ table value of 5.99 , It was therefore asserted that there was no significant difference between the changing livelihood patterns and conflict between the Pokot and the Turkana communities of Kenya. However the Pokot were more likely to enter into conflict with the Turkana as a result of livelihood patterns as indicated by the calculated $\chi^{2}$ values of 0.033 among the Pokot and $\chi^{2}$ value of 0.099 among the Turkana community. Therefore changing livelihood patterns influence conflict occurrences among the study communities. Both classes have been influenced by the combined pull of cultural tradition and the drive of contemporary influences, according to Mwaniki et al. (2007). In decisionmaking, male elders and opinion makers usually play a critical position. Traditional dispute mediation mechanisms and approaches now offer a significant starting point for the implementation of peace and development policies in the area, but they are not as vigorous as in the past. The youth, for their part, would argue that they would not wait indefinitely though they would be willing to allow their elders and the government time to recover the cattle or negotiate compensation.

They would then take a reprisal raid if it matched them. The youth would often force elders to approve such raids if no consequences were created by structured government processes. A series of livestock raids prompted the impacted community to prompt significant retaliatory responses. This was a feature of the rivalry between the divisions of Kainuk Turkana and Alale Pokot. Young people will offer different explanations for such assaults, citing, among others, poverty, malnutrition, and decreased numbers of livestock.

The findings computed from the questionnaires were collaborated with the qualitative data obtained by interview schedules in Kacheliba in Pokot North, a village elder in an FGD noted that;

The Pokot today considered raiding the enemy community as a way of increasing stock. The young men of the community made numerous raids on the Turkana, but contrary to raids in the old days, the young warriors sold all the livestock they stole from the Turkana. Source: Field Data 2017

The respondent lamented that this had reduced the number of livestock held by both the Turkana and Pokot. But traditionally that was not the case because there was a constant and sure supply and counter raids on each of these two communities. This had ensured that the livestock stolen from one community could be returned to the same community in the next raid. This had changed in recent times due to commercialization of the stolen animals, thereby increasing incidences of clashes, hence the prolonged conflict.

Both classes have been influenced by the combined pull of cultural tradition and the drive of contemporary influences, according to Mwaniki et al. (2007). In decision-making, male elders and opinion makers usually play a critical position. Traditional dispute mediation mechanisms and approaches now offer a significant starting point for the implementation of peace and development policies in the area, but they are not as vigorous as in the past. The youth, for their part, would argue that they would not wait indefinitely though they would be willing to allow their elders and the government time to recover the cattle or negotiate compensation.

They would then take a reprisal raid if it matched them. The youth would often force elders to approve such raids if no consequences were created by structured government processes. A series of livestock raids prompted the impacted community to prompt significant retaliatory responses. This was a feature of the rivalry between the divisions of Kainuk Turkana and Alale Pokot. Young people will offer different explanations for such assaults, citing, among others, poverty, malnutrition, and decreased numbers of livestock. 


\subsubsection{Natural Resources}

There is a clear correlation in Karamoja between globally evolving climate factors, scarce natural capital, instability of livelihoods and violence, according to a study by IGAD CEWARN (2004). The supply of services has been adversely influenced by volatile weather conditions and prolonged droughts. In the area, repeated crop failures have contributed to food insecurity. This is considered to have contributed to increased cattle raid accidents, and increased rivalry for water and pasture, and droughts have led to livestock destruction, promoting raids and counter raids. The lack of economic activity offers an incentive for raids, which become the economic activity of some individuals over time (Mwaniki et al., 2007). The value of livestock and natural resources as significant elements of the Turkana-Pokot dispute is verified by Schilling et al (2012).

The study sought to determine whether there was a link between limited resources such as lack of food, livestock of the Turkana and Pokot pastoralists and the continued conflict that had escalated for years between them. The study findings from the questionnaires indicated in Figure 4.1 showed that majority of chiefs and their assistants in Turkana $22(85.7 \%)$ asserted that poverty was a reason as to why conflict persisted Turkana and Pokot Communities of Kenya, while 25 (94.5\%) of the Pokot respondents in Pokot North felt that poverty caused and sustained conflict in the study area. These study findings were similar with the findings recorded from an interview with the Deputy County Commissioners who asserted that;

The hunger brought on by extreme droughts and Pokot raids suddenly rendered Turkana low. This indicated that the group watched the young men chase the animals that the Pokot robbed to return. The Turkana thus carried out a number of reprisals against the Pokot. Source Field Data (2017). 


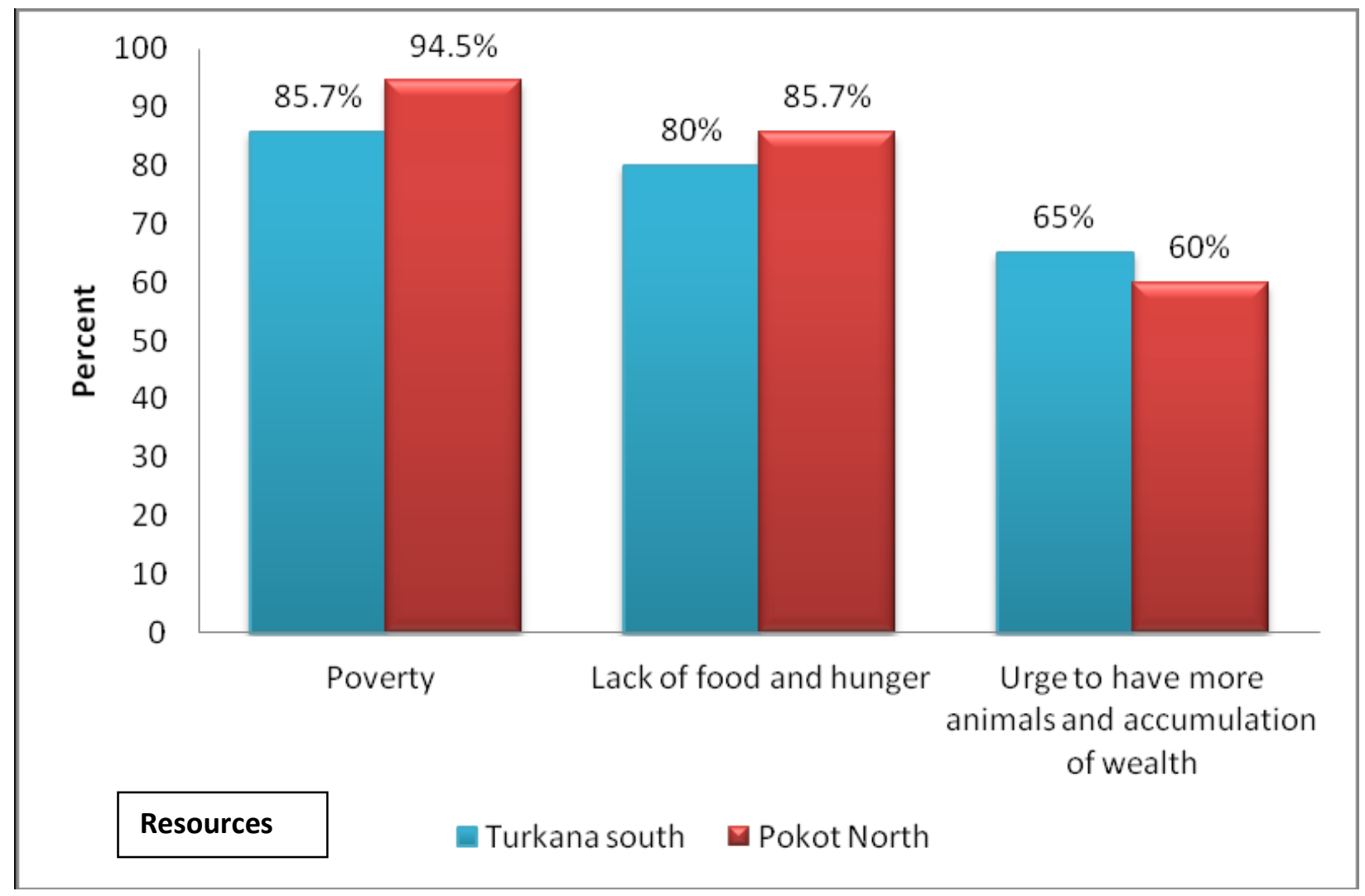

Figure 4. 1: Natural Resources and Conflict among Turkana and Pokot Communities of Kenya

\section{Source: Field Data (2017)}

The Turkana had become poor because of the changing and constant adverse weather conditions and numerous and constant raids from the Pokot, forcing them to search for alternate sources to replenish their supply. This lead to a protracted and sustained dispute between the two groups (Berger, 2003).

Information obtained by questionnaires from the chiefs and their assistants in Turkana south, it is noted that lack of food as indicated by $20(80 \%)$ was the reason for constant raiding and sustained conflict. In Kalemngorok in Turkana South, the chief of Kainuk location supported the study findings by asserting that;

Food deficits also caused conflict, so raiding incidences naturally increased as people attempted to cope during lean periods brought about by droughts. She explained that the Turkana do not necessarily slaughter their livestock for food, but only use milk and blood from the animals. It is usually on certain occasions that animals are slaughtered, for example during certain ceremonies. But when it did not rain for longer periods, it meant milk and blood was not available from the animals. This forced the Turkana to slaughter their animals, which meant they had to look for an alternative source to replenish their stock. Source: Field Data 2017

However in Kacheliba in Pokot North, a village elder in an FGD reported that the Pokot today considered raiding the enemy community as a way of increasing stock. The young men of the community made numerous raids on the Turkana, but contrary to raids in the old days, the young warriors sold all the livestock they stole from the Turkana. The respondent lamented that this had reduced the number of livestock held by both the Turkana and Pokot. But traditionally that was not the case because there was a constant and sure supply and counter raids on each of these two communities. This had ensured that the livestock stolen from one community could be returned to the same community in the next raid. This had changed in recent times due to commercialization of the stolen animals, thereby increasing incidences of 
clashes, hence the prolonged conflict. Therefore raiding the community with which they had sour relations became an available option. Thus the Turkana raided the Pokot due to hunger.

The chief also explained that the drought of 1999 to 2001 and 2004 to 2013 severely affected the people of Kalemngorok who moved their livestock to areas of Lorokon on the border of Pokot and Turkana. There, the Pokot found it easy to climb down from the neighbouring hills and attacked the vulnerable Turkana and took away everything. The Turkana moved back with fewer cattle and had to be given food relief by World Vision $(\mathrm{K})$ in order to sustain them until the next rainy season.

Raiding between the two communities had been happening from time immemorial, but the difference that year was that the Turkana from South called those from North and west Turkana. Together, they raided Konyao, Kacheliba and Kasei in Pokot North, in three waves, attacking simultaneously. This new way of raiding confused the security forces who were ill prepared for such an attack. The FGD participants reported that the raiders eluded the security forces and came home to a rousing welcome from the women and the whole community. They brought home large herds of cattle to replenish their dwindling stock.

It was clear from the FGD participants' descriptions and actions that the Turkana group loved raiding the neighboring Pokot and would do it again if an incentive presented itself. This form of action, thus the prolonged ethnic war, promoted conflict between the two groups. It also noticed that in order to elude and avoid the security services, the raiders were now using modern techniques in raiding. This discovery was a break from the typical raiding, where a few raiders from the neighboring village could raid one field and troop back home with livestock.

A village elder in a FGD told the researcher in Pokot North, in Alale, that the drought from 1992 to 1995 just before the great rain (El Nino rains) compelled some of them to flee to Uganda where they experienced Karamoja attacks, while others migrated to Turkana's rich areas along the Turkwell River. Here, Turkana women who went to gather firewood and wild berries were ambushed by the Pokot. This was achieved to scare away the Turkana from the Kaputir, Nakwamoru and Juluku arable fields.

This limited the ability of Turkana women to collect berries, which were used to supplement food shortages in dry seasons. The women feared to be abducted, raped and killed. In addition, the village elder in the FGD recorded that the Pokot warriors only raided the Turkana in the old days for honor and payment of the bride price. But today, Turkana was continuously assaulted by the young fighters, driving them indoors, leaving behind the vast arable tracts of land they decided to occupy. This was a modern method of raiding and the dispute was complex and thus prolonged, providing the foundation of the second goal that the thesis tried to establish.

\subsubsection{Dynamics in Pastoral Livelihoods that Trigger Conflict}

The researcher also sought to determine the changes/dynamics in pastoral livelihoods of the Pokot and Turkana communities that drive and sustain the conflict between the Pokot and Turkana communities and the findings were presented in Figure 4.2. 


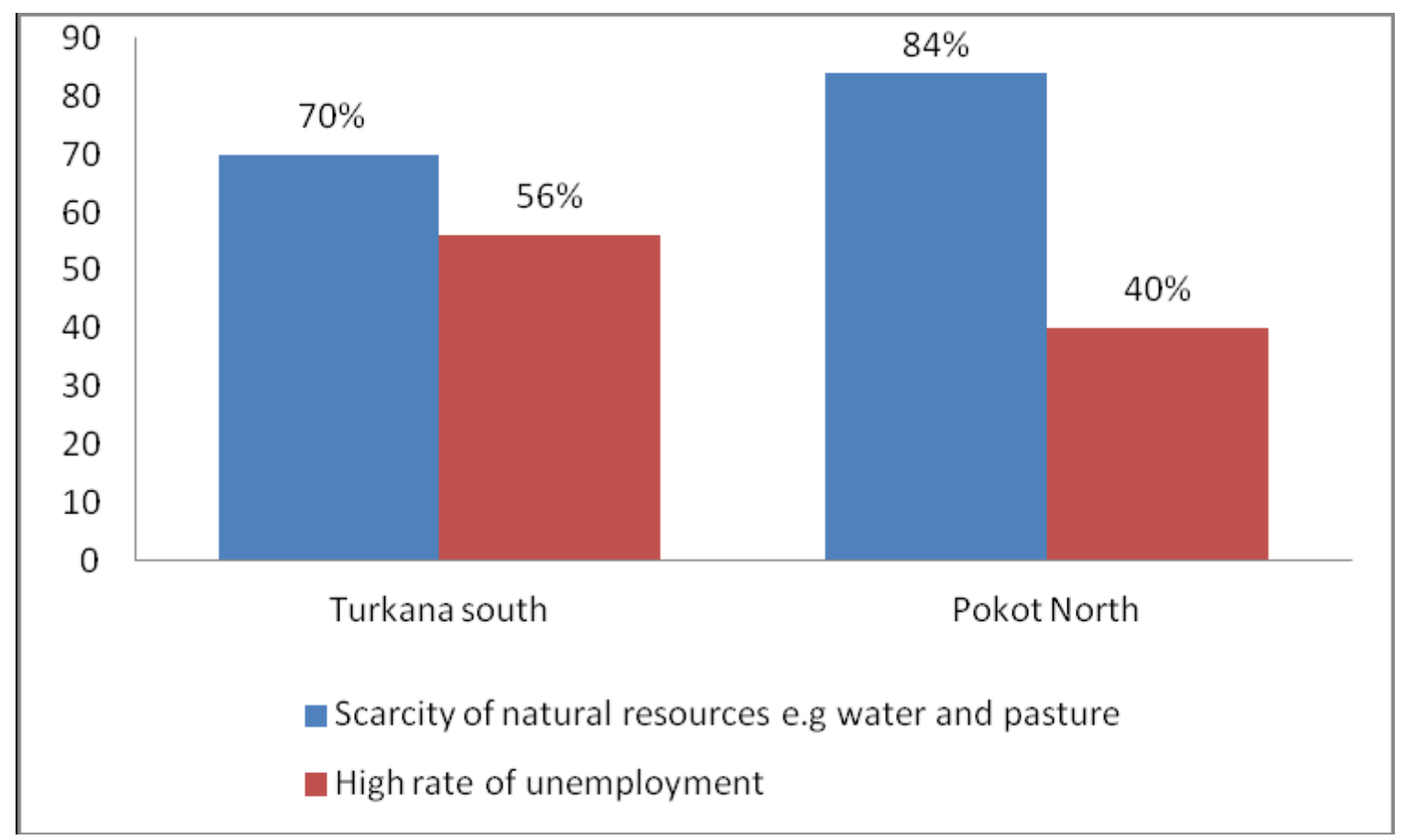

Figure 4. 2: Dynamics in Pastoral Livelihoods that Trigger Conflict

\section{Source: Field Data (2017)}

Figure 4.2 shows that 55(84\%) of the respondents in Pokot North felt that conflict between the two communities was as a result of scarcity of resources such as water and pasture and lack of food leading to hunger. A kraal leader in Kasei reported that conflict takes place along the River Turkwell which forms the border of these two communities.

The respondent also explained that the Pokot live mostly on hills and had no land for expansion. There has been expansionist behavior down from the hills towards the river Turkwell due to population pressure. The Turkana could not allow this downward movement and would rather die and not give up their land. The respondent explained that in 1992, the Pokot politicians requested the then president to allow them access the Turkwell River to use water and grazing grounds around it.

Although the then president asked the Turkana to use the river with their neighbours, the Turkana have never been comfortable with this arrangement.

The chief of Kainuk location supported the study findings by asserting that;

There have been many clashes between the Turkana and the Pokot around Lorokon, Kainuk, Nakwamoru, Juluk, Lokapel and Katilu, all in Kainuk division. There has been a confusion of where the Turkwell Hydro power station belongs. This also has been a source of conflict between the two communities.

Source: Field Data (2018)

This according to this chief had led to the loss of many lives and changed the frequency of conflict between the two communities. The youth in Pokot North had resorted to using groups of 4 to 5 young warriors to attack mainly women from Turkana south tending to farms along river Turkwell. They killed and maimed them to send a message to anyone who dares to farm on that land. This was a new way of killing the enemy because culturally the Turkana did not kill women, children and the old when they attacked the enemy. The Pokot customs were also similar to the Turkana in that they only killed men of a warrior age. But the 
emergence of young warriors who do not respect the elders, rules and regulations governing the community but the gun, had changed conflict (Mwaniki, 2008).

These young warriors went on raids on their own and killed women, children and the old indiscriminately. The respondent sadly reported cases of pregnant women being killed, their bellies ripped open and babies removed from them crashed on hard surfaces. This was not culturally accepted, but the respondent regrettably narrated that they got those complaints during peace meetings with the Turkana and Pokot.

The fight over river Turkwell therefore had changed the conflict from being purely raiding and counter raiding to a resource conflict. The Pokot neighbouring Turkana mainly live on the hills; hence have no land for expansion. It is therefore this expansionist behavior that has changed the conflict from the traditional raiding to frequent killing of Turkana farmers who have no livestock, but only depend on the river banks to eke a living. The respondent added that those areas claimed by the Pokot from the Turkana originally belonged to the Pokot, who abandoned them during droughts and famines many years ago. But they needed the land now due to population pressure. Therefore irrespective of official boundaries, they were going to fight for that land until they got it back. This kind of argument did not encourage peace at all; instead it fuelled the conflict more and more.

Figure 4.2 further shows that $36(56 \%)$ of the people interviewed in Turkana South attributed the protracted conflict between these two communities to unemployment among the youth, while $40 \%$ in Pokot North felt that unemployment caused idleness which led to constant raiding as a way of life. A chief in an interview in Alale, explained that;

Many young people in Pokot North do not have formal education, which means they have no skills to gain employment. The education facilities in the area are few and scattered; People did not know the value of education. Therefore, many youths were unemployed and the level of poverty was very high, leaving cattle rustling and raiding as the only source of livelihood.

Source: Field Data (2017)

This was identified in an interview with women from the Pokot North group in which it emerged that the triggers of the Turkana-Pokot dispute were insufficient food for feeding, non-quarantined movement in pursuit of pasture, animal insecurity, and decrease in animal development, increase in human diseases, increasing hunger and revenge attacks.

A deputy county commissioner for Turkana County, during this interview reported that;

Most of the youths in the area just came from the kraals and were over age to join any kind of school. The only option was to enroll them informally in mechanic courses where they learnt on the job and driving school. He also helped them to learn carpentry, building and construction. Some of these youths had been committing petty crimes in Amakuriat, breaking into shops and even stealing chicken from homes. Others had resorted to banditry, stealing a goat here and selling it in a far away centre, ambushing vehicles on the way to Amakuriat.

Source: Field Data (2017)

The researcher opined that all these were new types of crime committed by these youths because of possessing a gun. Another Kraal leader in Katilu ward, reported to the researcher in an interview that;

The youths in the kraals avoided schools and had resorted to acquisition of modern weapons. They did this by following raiders, assisting them as spies, carrying luggages for them and also running errands while on a raid. After a successful raid, they would be paid with a goat or two. They used this to buy a gun, which is believed to change their lifestyle completely. 
Source: Field Data (2017)

The respondent narrated how the youths would go on a multiple of raids, selling all the stolen livestock and satisfying their new lifestyle by buying new watches, mobile phones, bicycles, motorbikes and engaging in excessive drinking.

To sustain this new way of life the youths engaged in numerous raids in a short period thereby increasing fatalities and casualties on both sides. This sustained and prolonged the conflict between these two communities. It was observed that with this changed nature of raiding, conflict was bound to continue for as long as the gun gave the power to the bearer to wreak havoc on the opponent. This explains the protracted nature of this conflict.

\subsubsection{Ethnography and Conflict among the Pokot and Turkana Communities}

Most scholars based their research on either cultural or ecological considerations in the 1900s. Sandra et al (2003) and McCabe (2004) argue that cultural factors related to the conventional social constructs of pastoral societies are significant and that belief systems, personalities, warrior beliefs, status, and rivalry are established as drivers of violence between age groups. Bollig \& Osterle (2007), however, points out that although most fights were waged with basic weapons during the 1960s and 1970s, automatic arms such as AK-47 and G3 substituted earlier rifles in the 1990s and 2000s. Owing to its vital function in transforming the household economy, the gerontocratic structure and the value framework of pastoralists, the AK-47 has recently been referred to as a reform agent. This has been the case in Kainuk and Alale divisions as was revealed by the study.

The findings of this study as shown in Figure 4.3 indicate that $94 \%$ of the village elders interviewed in Turkana South felt that conflict was caused by the need to pay high bride price. This was high compared to findings in Pokot North during the same study which showed that $85 \%$ of the respondents felt that they needed to pay many cattle to marry and this had led to the prolonged and frequent conflict between the two communities. When asked to explain the reasons for this disparity, a respondent in Pokot North, Tumkou Lomada a village elder who was also a former warrior reported that in the Pokot community initiation of females through circumcision which was done on girls as early as from 9 years necessitated that they be married off immediately. The same happened to boys who were already circumcised at the age of 15 , helping them to be citizens who might marry and start getting families. Without their own cattle, the young initiates resorted to stealing for marriage from nearby groups such as the Turkana. The culture was forbidden to rob from your own community or murder your buddy Pokot. The respondent also offered another explanation why it was polygamy for the Pokot to require several heads of cattle to marry. In the Pokot culture, the more wives one had, the more honor and reputation he received. The culture of Pokot also allowed an individual to have several children who were taken to be a source of riches. 


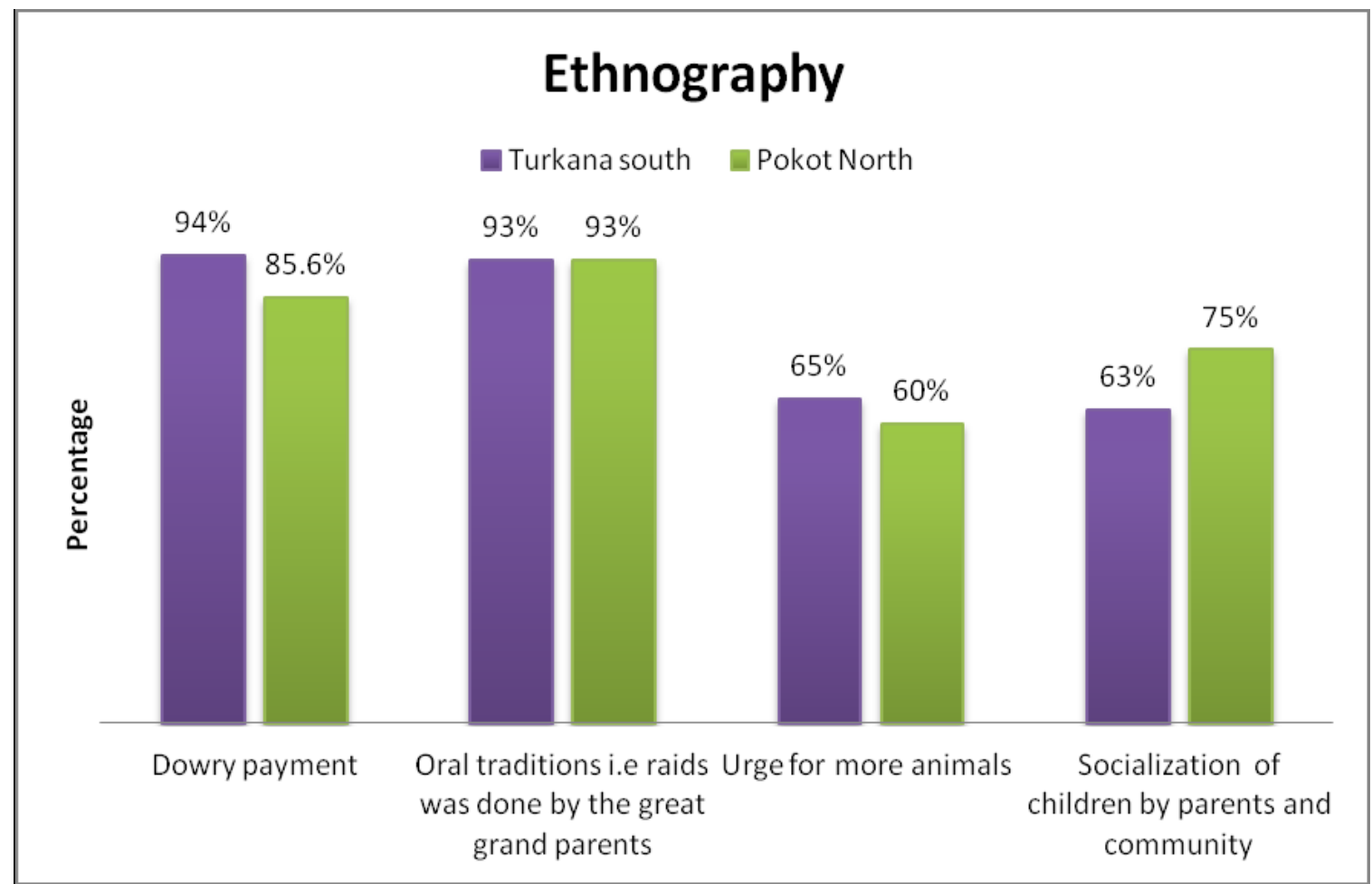

\section{Figure 4. 3: Ethnographic Influences on Conflict}

\section{Source: Field Data (2017)}

When asked why the Turkana needed a large number of cattle to marry, a village elder in Turkana South, during this interview narrated to the researcher as follows;

In the Turkana there was no tradition of circumcision, so that they would not fall into marriage early in their lives. The need for big bovine heads to marry was therefore not the product of the pressure to get married early, but of the expense of several bovine heads as a bride for a woman. The more the bride spends, the more reverence he receives in the culture of Turkana. The woman is still very much respected by her current spouse.

Source: Field Data (2017)

The culture often supports polygamy; the man therefore wants many bovine leaders to get many women. The respondent reported that the many cattle paid out as bride price among the Turkana people was given to the whole family tree of the bride. This accounted for the need of many cattle a man needed to marry. To marry one woman, a man needed about 50 heads of cattle, 70 camels, 10 donkeys, 200 sheep and 300 goats. This means the lineage of the man had to contribute some of the livestock needed for bride price. In order to replenish the stock of the man's kin, the young men of the said family were required to execute a raid after the wedding. The persistent and regular tension between the two groups led to this.

Figure 4.3 above indicates that in Turkana South, 93\% of the respondents explained that violence was passed to successive generations through oral narratives such as heroic stories told by grandparents to young children in form of past stories in order to instill bravery into them. These oral narratives were passed from one generation to another with specific names of the brave and great men of the community.

It was stated during a focus group discussion in Nakwamoru that the cultural emphasis on livestock among the Turkana emphasizes the cultural appeal of cattle raiding that encourages violence, as the cultural qualities associated with raiding encourage young men to raid. Raiding and conflict will be taken by the young men as a move into prominence, tattooing and acquisition in the culture of warrior (heroic) titles. In Kacheliba, a similar FGD showed that raiders and their representatives were not taken as offenders but as heroes and men of honor in the Pokot culture. For defense and safety, the community believed they required 
these men and proverbs, poetry and romantic songs written or sang in honor of these raiders not only rendered their families proud, but also inspired culture to instill the warrior hood spirit into the young people. A similar number of respondents of $93 \%$ in Pokot North also agreed that violence was passed to young children in their community through oral traditions. The findings also showed that $63 \%$ of the people interviewed in Turkana South saw socialization by parents through songs, stories, and induction and community expectations contributed to the protracted and frequent conflict between the two communities. Young men without cattle were despised and rebuked for not being much stronger than women as a justification for socialization. Pastoral groups have a long tradition of disputes in north-western Kenya. In the broadest context, as a consequence of opposing viewpoints, dispute can be described here as forceful contact. The disputes are mainly over livestock and its associated valuable properties - water, field and pasture - as pastoralism revolves around livestock. Such tools strongly relate disputes to the aggressive stealing of cattle, known as raiding, and is both a contributing factor and a conflict articulation. Raiding, on the one side, contributes to mistrust between classes, which is a precursor for confrontation (Mwangi2006). Communities, on the other hand, use raids to demonstrate their animosity against enemy communities (Eaton 2008).

\subsection{Conflict $s$ among the Pokot and Turkana Communities}

Although Butler and Gates (2012) see demographic pressure, climate change and resource shortages as the basic sustainers of inter-ethnic abuse, these claims have been dismissed by several empirically validated research, arguing that structures and political calculations are critical in steering the responses of citizens to these variables to either dispute cooperation. This thesis analyzed both culture and ethnography as influences that affected the rivalry between these two groups. The study therefore further sought to determine the sustainers of conflict among the Turkana and Pokot communities of Kenya. To answer this theme the respondents to respondent to the following statements as indicated on a likert scale of of SA= Strongly Agree, $\mathbf{A}=$ Agree, $\mathbf{U}=$ Undecided $\mathbf{D}=$ Disagree and $\mathbf{S D}=$ Strongly Disagree. In this study descriptive statistics and chi-square was used in data presentation as indicated by (fo) for observed frequency and (fe) for the expected frequencies in computation of chi-square values. Table 4.3 shows the study findings.

Table 4. 3: Sustainers of Conflict among the Turkana and Pokot Communities of Kenya

\begin{tabular}{|c|c|c|c|c|c|}
\hline SUSTAINERS OF CONFLICT & $\mathbf{S A}$ & $\mathbf{A}$ & $\overline{\mathbf{D}}$ & \multicolumn{2}{|c|}{ TOTAL } \\
\hline & fo $\mathrm{fe}$ & fo $\mathrm{fe}$ & fo $\quad \mathrm{fe}$ & $\mathrm{N}$ & $\mathrm{X}^{2}$ \\
\hline Politics & $50 \quad 54$ & $59 \quad 55$ & 21 & 130 & .636 \\
\hline Governance & $55 \quad 54$ & $50 \quad 55$ & 25 & 130 & 1.723 \\
\hline Peace Building & $60 \quad 54$ & $59 \quad 55$ & 11 & 130 & 5.006 \\
\hline $\begin{array}{l}\text { Commercialization of } \quad \text { raided } \\
\text { animals }\end{array}$ & $50 \quad 54$ & 59 & 20 & 130 & .636 \\
\hline Proliferation of small arms & $55 \quad 54$ & $50 \quad 55$ & 25 & 130 & 1.723 \\
\hline TOTAL & & & & 130 & 9.724 \\
\hline
\end{tabular}

Source: Field Data (2017)

As portrayed in Table 4.3, the descriptive and chi-square statistics derived from the questionnaires showed that there is was no statistical difference between the sustainers of conflict and conflict occurrence between the Pokot and Turkana communities in Kenya since the calculated $\chi^{2}$ values of 9.724 at .95 degree of 
freedom was lower to the critical $\chi^{2}$ table value of 16.9. Therefore conflict sustainers influenced the conflict between the two communities. Kenya Environment Government (2007) documents examine shows thatKenya is adversely impacted by many decades of regional turmoil. According to oral interview with the County Commissioners of Turkana and West Pokot Counties, They reported that;

There are continuous movements of firearms over the broad, open boundaries of Turkana, so that Kenya's Turkana population has been the most militarized. They also describe the small government involvement of Turkana and its first line of defense is highly reliant on the KPR. In fact, in Pokot North and Turkana South areas, this has led to more arms.

Field Data 2017

According to Gray (2000; IGAD CEWARN, 2004; Jabs 2007; Mkutu, 2007), the type and method of raids has shifted dramatically from small sanctioned raids utilizing knives, bows and arrows, machetes and other crude arms to large armed raids or livestock stealing (Stites et al., 2007). Bollig \& Osterle (2007) reported that, at the same period, inter-group conflict is profoundly rooted in local communities and thoroughly modern in Northern Kenya. Weapons have been of critical significance in the area since the 1960s. Although most fights were still waged with basic weapons throughout the 1960s and 1970s, automatic arms like the AK-47 and the G3 replaced older firearms in the 1980s and 1990s.

Traditionally, cattle raiding was treated as a cultural activity by pastoral groups and was permitted and regulated by the elders. The attacks were carried out mostly in the dry season because it was quicker than when it was rainy and dusty to navigate across the brush and wilderness. That was also one way to prevent identification, since cattle hoof prints are more visible on wet surfaces than on dry surfaces (Hulme \& Fukudu, 2009). During this study, the research established the sustainers of conflict as presented in Figure 4.4 below.

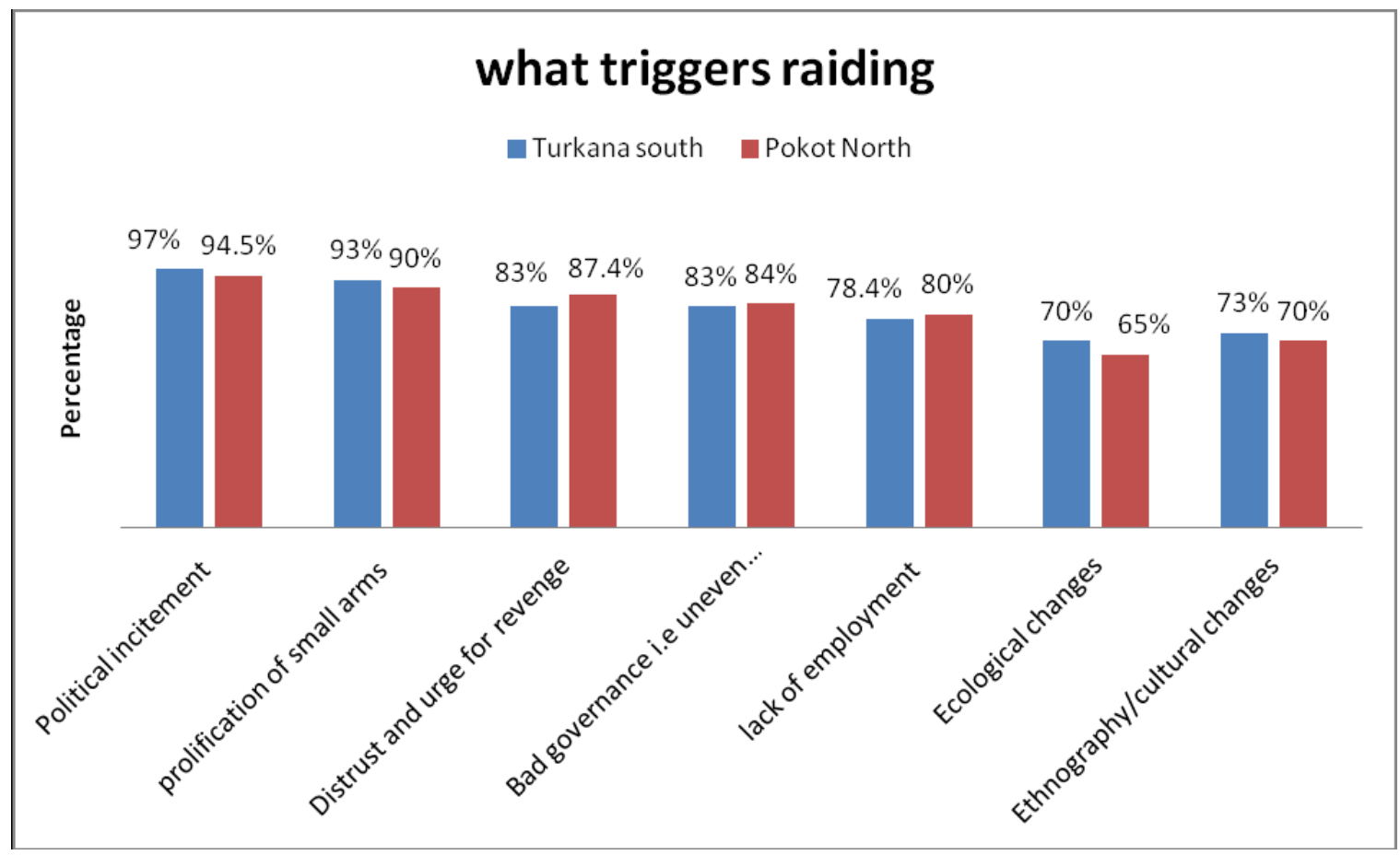

Figure 4. 4: Sustainers of Conflict in the study area

Source: Field Data 2017 
As seen in Figure 4.4, the results of this study revealed that 97 percent of Turkana South respondents thought that the Pokot politicians' political benefits promoted tension between the two groups. Violence was sparked by political utterances and continued inflammable comments guaranteed that the violence continued as a means to demonstrate power and might over the opposing party. Of the respondents in Pokot North, about 94 percent thought the same. As revealed by a focus group discussion from Turkana South at Lokapel, where the Pokot from Kacheliba is reported to have carried out various and regular raids on the Turkana villages of Nakwamoru, Juluk, Kaputir, Katilu and Kainuk between 2001 and 2013, there was a counter blame on either side.

From a FGD with a group comprising 8 village elders in Kacheliba, Kongelai, Chepararia and Chesogon, explained that Pokot North borders Karamoja in Uganda, from where modern arms enter Kenya. These arms made their way into Kenya's Pokot and Turkana regions after the collapse of the governments of Obote and Amin. The ease with which these weapons were reached by the Turkana and the Pokot ensured continuous supply and usage. This implied that to test the latest weapons obtained and vice versa, the Turkana would strike the Pokot. Due to the availability of idle and illicit arms in both communities, the war has turned disastrous and frequent. It was difficult to find a gun to purchase in the Turkana or Pokot area before the chaos of the neighboring states in the region, namely South Sudan, Uganda, Ethiopia and Somalia. But the abundance of these arms has fuelled the rivalry between, on the one hand, the Pokot and the Karamoja clans and, on the other, the Pokot and the Turkana clans.

The study further revealed that the style of fighting had also changed to sporadic attacks which lasted shorter times and stolen livestock could not be traced. In the traditional days, stolen livestock could be traced in the neighbouring community and could find their way home in the next raid. But this was not the case in the new way of modern livestock theft. Livestock were sold as soon as they were stolen. The FGD explained that traditionally this interfered with the cultural way of herd management by these two communities due to the reducing number of livestock, without means of replenishing.

The mode of attack also had changed where the warriors would attack a village, killing the old, women and children. Pregnant women were killed and their bellies opened, the children removed from their bellies and crashed against stones or hard surfaces. This was done to show brutality to the enemy and terminate any male offspring from the enemy community. In traditional days, the old, women and children were not killed during a conflict. But this was no longer the case. This was what made the conflict under study different from other traditional conflicts. The changes in raiding patterns and modes of carrying out attacks on the enemy had become lethal (Mwaniki, 2008).

The FGD also reported that it seemed the Pokot politicians were more powerful than their own, because they could make inflammatory statements in public, but no one arrested them. But when the Turkana politicians made the same statements, they were arrested and faced court charges. One elde from the FGD gave an example in 1997 when the then Member of Parliament for Turkana South, the late Francis Ewoton, was accused of making statements that threatened peace. He was arrested and arraigned in court in Nakuru. As the village elders in Pokot North blamed Turkana South political leaders for insecurity in Pokot North, the respondents in Turkana South also blamed past and present Pokot political leaders for the insecurity in Turkana South.

In an FGD in Kalemngorok comprising of 8 village elders, reported that;

In 1997 disarmament exercise, the security officers disarmed only the people of Turkana south and not the Pokot. Previous disarmament exercises of 1984, 1989 and 1995 were brutal but carried out in both Pokot and Turkana regions. The Ugandan government has also been carrying out similar disarmaments on the Karimojong since 1986. The two governments have been carrying out disarmaments in uncoordinated manner. Meaning the Karimojong became vulnerable to the Pokot during their disarmament period. The Turkana were also vulnerable to the Pokot during the 1997 and 2002 disarmament exercises. 
Source: Field Data 2017

The FGD lamented that the Pokot raided the Turkana numerous times from 1992, 1993, 1995 and 1998. These raids weakened the Turkana and made them poorer and vulnerable to hunger and disease.

In comparison, the results in Figure 4.4 revealed that 83 percent of the participants in the interview in Turkana South thought that vengeance was a driving force as to why for several decades the fight continued to go on and on. 87.4 percent of the respondents thought the same in Pokot North. The study also showed that 83 percent of Turkana South respondents saw the government's uneven disarmament efforts as a catalyst for individuals to procure new and more advanced arms to replace the old ones handed in during disarmament. Of the respondents in Pokot North, about 84 percent thought the same way.

The Kenya Government's Status of the World Study on Kenya (2007) shows that Kenya has been negatively impacted by many decades of political turmoil. There are sustained movements of firearms through Turkana's broad, open boundaries, according to Mkutu and Wandera (2013), so that the Turkana population in Kenya has been the most militarized. Turkana has a limited government footprint, they also explain, and is highly reliant on the KPR force as its first line of defense. This has led to more weapons in civilian hands, especially in the regions of Pokot North and Turkana South.

During this study, it was established that porous borders contributed to the easy flow of arms as shown in Figure 4.5. About $29(45 \%)$ of the village elders in Turkana South attributed the proximity of Turkana County to international borders such as Ethiopia, Uganda and South Sudan as exacerbating conflict within Turkana South.

The current women member of parliament for Turkana County explained that;

My constituency borders the Pokot pastoralists to the south, Loima constituency to the west, which shares borders with Uganda and arms from Uganda, South Sudan and Ethiopia ended up in Turkana South through various movements from Uganda, South Sudan and Ethiopia into Kenya.

Source: Field Data (2017) 


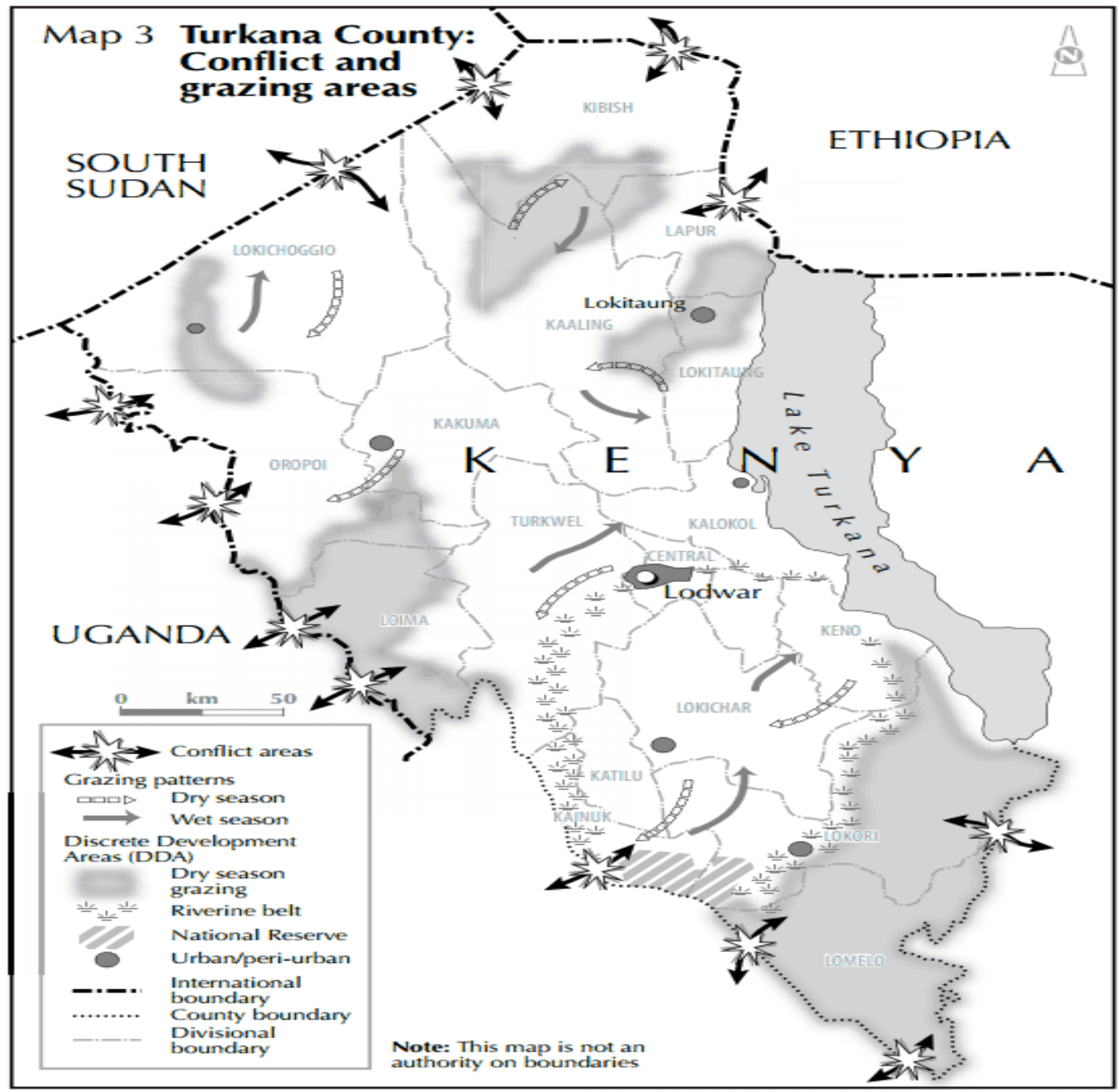

26 Small Arms Survey Working Paper 15

Figure 4. 5: Proliferation of small arms through international borders

\section{Source: Small Arms Survey working Paper 2015}

In support of this argument the interview with the women representative of the Pokot County reported that;

The growth of a market economy and the commercialization of raiding have accelerated the loss of herds. Raided species have traditionally persisted within the same ecological zone. This implied that it was easier to retrieve missing livestock. As meat exports to areas beyond Africa increase, however, raiding has taken on another dimension. A network of companies that provide a ready demand for raided animals has been generated with the advent of cash for animals. When raided, cattle are forced over boundaries and smuggled outside the control of pastoralists to markets. Orthodox rescue attempts and negotiating strategies are futile in this case. Raiding has become an occupation that produces revenue instead of a way of raising social prestige or performing cultural functions. Knowing that raided cattle in a money economy are important economic properties and that raided livestock can never be 
returned, pastoralists are compelled to tightly protect their remaining stock and that is why many guns have made their way to the county.

Source: Field Data (2017)

The document analysis based on Small Arms Survey Working Paper 15 also indicated that; Pokot North citizens have thought that Pokot North's weak boundaries and accessibility to Uganda led to the proliferation of small weapons.

An interview with the County Commissioners also revealed that arms from as far as South Sudan found their way into Alale through the Karimojong region of Uganda. The County Commissioners asserted that;

The growing introduction of firearms complicates environmental pressures and the spread of trade in livestock exports. Since the Horn of Africa War Concert and northeastern Uganda, all of northern Kenya has been a weapons bazaar. The quantity and standard of guns have been improved by two inventions. First of all, the surge of asylum seekers from conflictafflicted nations has exceeded the Kenyan government's ability to monitor the arms that come with these communities. Combatants have arrived with these parties, including gangs, soldiers, and remnants of troops from countries at war. These men bear together with their advanced weapons the expertise and experience of fighting battle. The influx of all these armed groups implies that rather than the traditional raiders, the pastoralists have to deal with Source: Field Data (2017)

Another CEWARN (2007) documentary analysis shows that government action has always taken a very hard handed manner in the past and even current, marked by military campaigns of troops violently targeting whole villages and populations as culprits.

In an FGD in Nakwamoru, it was reported on proliferation of small arms through international borders that the Turkana fabricate guns which they used to raid the Pokot and other neighbouring communities. Then, raiding was not as frequent as it is now. But with the advent of merchants bringing arms for sale from as far as Somalia, South Sudan and the Karmoja area of Uganda, they only needed to give 3-5 oxen for an arm depending on its cost. The FGD also reported that it had become easy to acquire an arm in Turkana these days, probably because of the fighting still taking place in those countries. They spend cash instead of cattle now because the arms have become cheaper and easier to access. One AK-47 would go for Ksh.100, 000 (1,000 dollars) while a G3 would go for Kshs. 70,000-80,000 (700-800 dollars). With the cheapness and abundance of arms in the region, there was a constant supply throughout. This led to the proliferation of small arms in the region, which instigated and sustained the conflict in both regions.

This culminated in the anger and distrust of innocent citizens towards the nation.. Groups of people in the community were subjected to communal payments of livestock to compensate the enemy community which had lost livestock raids. This activity goes back to the colonial period and was perceived by the nation as penalizing citizens, families and groups who did not partake in the crimes perpetrated. The society wanted the government to secure its citizens' lives and properties.

The Pokot North respondents also thought that, as reflected by $60 \%$ of the respondents, the weak boundaries and proximity of Pokot North to Uganda led to the proliferation of small weapons. An interview with a former raider in Kacheliba showed that guns made their way into Alale via the Karamoja area of Uganda from as far as South Sudan. The respondents also informed the researcher that some Somali traders brought arms from as far as Somalia to sell in Pokot North. The respondent further reported that with the Somalis bringing arms from Somalia and others from South Sudan, there was a constant supply of arms and ammunitions and an alternative source. The competition among suppliers had led to the reduction of prices and so one could purchase an arm with as little as Ksh 90,000 (900 dollars) to acquire an AK-47 in Pokot North as shown in Table 4.4. 
Table 4. 4: Small arms proliferation into Turkana and Pokot Regions of Kenya

\begin{tabular}{|l|l|l|}
\hline Proliferation of Small Arms & Region & Percentage \\
\hline Porous borders & Turkana South & $(46) 70$ \\
\cline { 2 - 3 } & Pokot North & $(39) 60$ \\
\hline \multirow{2}{*}{ Commercialization of raided cattle } & Turkana South & $(26) 40$ \\
\cline { 2 - 3 } & Pokot North & $(52) 80$ \\
\hline \multirow{2}{*}{ Kenya Police Reservist Arms } & Turkana South & $(33) 50$ \\
\cline { 2 - 3 } & Pokot North & $(33) 50$ \\
\hline \multirow{2}{*}{ Low Cost of Arms } & Turkana South & $(43) 65$ \\
\cline { 2 - 3 } & Pokot North & $(33) 50$ \\
\hline
\end{tabular}

\section{Source: Field Data 2017}

Marketing of raided livestock was often used as a significant factor in purchasing more weapons for the residents in these two communities.. Table 4.4 shows that (52) $80 \%$ of the respondents of Pokot North felt that they needed to raid for wealth, while (26) $40 \%$ of the people interviewed in Turkana South felt that the Turkana raided to sell the animals. A village leader, interviewed in Katilu, Turkana South explained that the Turkana raided the Pokot due to hunger and drought. The more the Turkana raided the enemy community the more livestock they got and the more food supply. The livestock realized from raiding could be used to replenish dwindling stock, animal products could be used to feed the children, women and the old. Cultural practices such as initiation ceremonies held and wedding costs could be conveniently compensated through the continuous availability of livestock from raiding. This inspired young people to buy their own guns because the gun allowed them to get their own animals and even marry early. The respondent clarified that for guidance or behaviour control, the youth did not have to depend on their parents for inheritance or on elders. Via the weapons, they might get something.

Therefore, further youths ordered weapons that were made accessible by businessmen on request. This rendered weapons turnover very large in the area, hence the proliferation of small arms in the south of Turkana as a whole. But in Pokot North, a village leader explained in Alale that the Pokot were raiding for dowry and wealth accumulation. A pistol was seen as a sure way to quickly get wealthier. His acquisition was then seen as necessary to gain immediate wealth. The respondent reported that many youths in Pokot North saw instant wealth in raiding. He narrated that in between 2002 and 2006; many youths had dropped out of school and ran to Karamoja region in Uganda where they came back with arms.

These youths engaged in sporadic raids and even changed the magnitude and face of raiding from what was known in Pokot North. The youths could raid Kainuk three (3) or four (4) times a week. They returned home with many herds of cattle which they could share among themselves, each realizing as many as five (5) to seven (7) heads of cattle. Then sell instead of keeping increasing the herds. This was because the youths had changed the mode of raiding from taking many people on a raid, to just about five (5) to six (6) only in a group. The youths had discovered that the fewer they were the better for maneuver and in division of livestock.

The livestock realized from raiding was sold as soon as it crossed over from the enemy community. The money realized from the sale was used to start other business ventures like shops, buying motorbikes used in business, building semi-permanent houses for the raiders and for big businessmen buying tracks to ferry livestock as soon as they reached Pokot North. The change of raiding from traditional method to the new commercialized activity had made raiding lucrative, frequent and deadly. This sustained this conflict and prolonged it 
The study further revealed that the establishment of Kenya Police Reservists (KPR) in the two communities led to the availability of small arms in the two areas. Respondents in both communities saw in equal portion, arms held by KPR as a cause of the conflict and adding to the sustenance of the conflict. Fifty percent of the interviewees in Turkana South and Pokot North related the weapons in KPR's possession to the escalation and prolonged essence of the fight. This is because no one monitored when these weapons were utilized for the intended use.

A former KPR in Katilu, reported that the KPR give the community a service that would otherwise be provided by the police, but since the police officers sent to the area were few, the KPR supplemented their services. But they are not paid for their services and so the KPR used ammunition given to them to get money to sustain them.

In towns like Lokichar where there is oil, the KPR are hired and their services paid. In big towns like Lodwar, the KPR are hired to guard shops, banks and provide escort security for vehicles travelling to Kitale and back. This they do for a fee. The respondent regretted that this was not the role the KPR was meant for. This led to misuse of the arms in the hands of KPR and selling of the ammunition to criminals, thereby leading to the ready availability of small arms in Turkana County.

A KPR in Lokapel was found selling a bullet at Ksh 4 to buy alcohol. When asked why he did that, he explained that they were not paid for the work they do. Due to the small number of police and other security officers in such areas, the KPR were expected to help carry out these duties but without pay. The KPR also reported that they sometimes engaged in paid activities like escorting vehicles from Lodwar to Kitale and back in order to earn some money to sustain them.

In an interview in Pokot North, in Alale, a former KPR, narrated that because the government arms KPR, but does not pay them, the KPR had found ways of sustaining themselves by engaging in various illegal activities. He reported that some of the KPR in North Pokot could accompany raiders to Karamoja for a raid. They would be given a share after a successful raid. Others also gave ammunition to raiders going for raids to Turkana. Others sold the ammunition to get cash they badly needed for survival.

The results in Table 4.4 further show that arms in Turkana South have a low cost compared to Pokot North where they also cost cheaply as explained by the people interviewed. A village leader in Lokapel in Turkana South, informed the researcher in a FGD that the low cost of arms had made it possible for the buyers to acquire them easily and cheaply, hence the availability. About $65 \%$ of the respondents in Turkana South reported that the low cost of arms made the buyers acquire the cheaply and readily.

This led to the increase of illegal arms in the hands of the unintended handlers, encouraging those who bought guns to go raiding in order to get back the money they spent. The respondent reported that an AK-47 costs between Ksh 150,000-200,000 (1,500-2,000 dollars) in Turkana south, between Ksh 100,000-150,000 1,000-1,500 dollars), and Ksh 75,000-100,000 (750-1,000 dollars) in Turkana. A G3 costs much less, Ksh 100,000 (1,000 dollars) in Turkana South, 75,000 (750 dollars) in Turkana central and Ksh 50,000 (500 dollars) in Turkana North. Those who wished to buy arms from Turkana south sometimes went to where the arms were cheaper, in this case Turkana North.

Thirty three (50 percent) of respondents in Pokot North stated that the low cost of weapons in their region increased criminal activities among young people. A former weapons dealer claimed that it was simple for him to procure arms from the Karamoja area to sell to Pokot warriors. A pistol will then cost Ush 560,000 $(\$ 5,600)$, which was Ksh 20,000. (200 dollars). But now the raiders have gotten cheap weapons from the Somali merchants in Pokot North. It was necessary to swap a pistol for 2-3 oxen that were readily accessible in the village. It inspired young people to raid the Turkana to get livestock to be moved with arms. In Pokot North, the weapons industry was rather enticing and the arms traders used arms quickly and conveniently and there was a ready demand. This facilitated small arms proliferation in the area, hence the prolonged ethnic violence between the two parties. 
From the research findings regarding proliferation of arms in to the Turkana and Pokot regions in Table 4.4show that majority of respondents in Pokot North 48 (74\%) attributed inadequacy of security personnel to the prolonged conflict between the Pokot and the Turkana. While $40(62 \%)$ of the respondents in Turkana South Sub County felt that the conflict escalated in recent years because the security officers sent to the region were few and could not meet all the insecurity needs of the area, taking into consideration that Turkana shares international borders with three countries. The findings further show that $22(82 \%)$ of the assistant chiefs interviewed in Turkana South thought that political marginalization had contributed to the conflict escalation since they were left to dispute for land for long periods with the Pokot.

The study results on weapons proliferation in the Turkana and Pokot regions in Table 4.4 also revealed that its durability was responsible for peace building as a mechanism to reduce violence between the Turkana and the Pokot regions. In Turkana South, $29(45 \%)$ of the people interviewed saw peace-building strategies along the Kenya-Uganda border as a major and thriving market. More respondents in Pokot North 50 (78\%) thought from the results that peace building was only a company like any other for the NGOs, CBOs and FBOs functioning in Turkana and Pokot. The older woman in Kasei claimed that;

New groups were formed each year, while others vanished in Pokot North because of corruption and mismanagement. Despite the lack of tangible results, millions of dollars continued to flow into these peace groups' bank accounts. Any gatherings would then be held by both organisations and representatives from both sides would be called to participate. They disappeared after that and the raid would immediately take place between the Turkana and the Pokot. The community really wondered why the NGOs, CBOs and FBOs bothered to hold peace meetings.

Field Data (2017)

The respondent further asserted that;

In towns far away from the conflict zones, peace meetings were held. In addition, the people who called for these meetings hardly had a clue as to what happens in areas of conflict. In the nice hotels where meetings were conducted, the attendees only appreciated good food and lodging, and even the fat allowances provided to them. They vanished to their homes after that,.

Field Data (2017)

The respondent further posed a question to this researcher;

Why can't those who call for those meetings bring them to where conflict occurs and also call the warriors, the ngimurok, the kraal leaders and the raiding youths to such meetings. That would drive the message to the real players and may be those who carry out raids could learn something and feel guilty of the act?.

Field Data (2017)

The Laikipa Peace Caravan was first convened by the Laikipia West Member of Parliament, Nderitu Mureithi, according to Okumu (2012), who succeeded in putting together practitioners from the communities of Pokot, Turkana, Samburu and Kikuyu to facilitate peace-building initiatives by conducting meetings with "peace caravans." Morans were called to these gatherings, and ceremonial reconciliation ceremonies such as livestock sacrifice and shared meal feeding took place. Professionals then took center stage and discussed the meetings together, encouraging their families to imitate productive inter-community partnerships as shown by the professionals themselves. The Peace Caravan has since operated in these areas, in each location, with community elders and "reformed" moran. 
The research findings regarding proliferation of arms in to the Turkana and Pokot regions in Table 4.4 show the study findings in Turkana South where 54 (83\%) of the respondents saw lack of political good will from the government as a factor which has led to the conflict being protracted and prolonged. A FGD with assistant chiefs in Turkana South revealed that;

Since 1990, however, Kenya's northern belt has been ecologically fragile; it has received more than 500,000 refugees in areas that help 10,000 individuals with difficulties. The population of the Kakuma division, for example, is more than 20,000; the Kakuma refugee camp, which occupies a region of 12 square kilometers, is home to more than 100,000 refugees (UNHCR 2009). The effect on such vulnerable ecosystems with such vast communities is momentous. Nevertheless, humanitarian relief, administered primarily by foreign organizations, is meant for migrants. This excludes the case of locals whose material state is generally worse.

Field Data (2017)

These observations reinforce the idea that pastoralist groups are in disagreement about the scarce supply of land to graze their livestock and promote their own well-being. The finding of oil reserves in the Turkana area along the Pokot community's boundary is maybe even more troubling. Therefore, both regions asserted deposits and another point of conflict over access to scarce capital is defined by themselves (Pragya, 2010). Oil could prove advantageous to the society that takes advantage of land lease agreements, so both Turkana and Pokot are very much at risk.

In Pokot North $53(82 \%)$ of the village elders blamed the continuous nature of the conflict on lack of political good will from the government. One respondent from Alale, a kraal leader reported that;

The authorities were not putting seriousness it normally displays when communities of agricultural sector experience conflict. The government was usually very quick in response to end such conflicts while pastoral conflicts were left to themselves. The respondent explained that conflicts affecting pastoral communities in Kenya and in particular parts of the Rift Valley were examples of violence which had been left to continue terming them as cultural. The findings further shows that 92\% respondents in Turkana South felt that political incitements by the Pokot politicians against the Turkana community led to more and more violence, revenge and counter revenge.

Field Data (2017)

In offering orientation, culture plays a significant and basic function, warding off confusion and, most significantly, steering actions into some lines of action and away from others. We will see the benefits and vulnerabilities of a community through culture; hence, culture becomes a complex place for contact between different interest groups and forces (Njogu \& Mazrui, 2008). In order to inspire feelings of solidarity and shared help, communities and cultures require reciprocal representation of themselves.

Osamba (2000) observed that there is still consistency in certain ways, even when cultural or social trends shift with time. He claims that a number of pastoral cultures have been militarized and heavily dependent on weapons in the last two decades. Culture is coded symbolically and may thus be communicated from one party to another. It does not stay stagnant, rather continually evolves and is ever-dynamic.

The factors of cultural transition involve environmental conditions, technical innovations, and interactions with other societies, but are not restricted to them. According to Abbink (1997), pastoral communities are an enduring, irresolvable obstacle for national political systems in Eastern Africa, situated by default in ecological and economic fringe regions. None of the nations have really progressed in including these 
communities in national decision-making systems, and none have definitely foreseen a future for them that guarantees their nomadic pastoral tradition.

The findings were supported by a village elder in Nakwamoru village who reported that;

In 2006, there were numerous attacks on the village because the Pokot politicians advised their electorate to raid the Turkana frequently so that the villagers could vacate the arable land for the Pokot. He named the then MP, Hon Moroto as the one who made the sensitive remarks in a baraza officiated by the then PC, Noor Hassan Noor, in Kainuk.

Field Data (2017)

These raids persisted for the better part of 2006 to 2007, when a meeting between politicians of the two communities in Nakuru, organized by the then Provincial Commissioner (PC), tried to point out the Pokot boundary with the Turkana. The Pokot leaders left the meeting displeased and the following day, there was an attack on residents of Napeitom in Turkana East, which was suspected to have been a retaliatory attack as result of the Nakuru meeting.

Huho (2014) suggested that much of the shared lands are located in the lowlands where pastoralism predominates, whereas the possession of freehold property is primarily in the highlands where land is arable. During the dry spell, the need to reach the land resources available created disputes between members of the group residing on the lowlands of Sigor, Cheptulel, Kacheliba and Chepkopigh and on the highlands of Chepateria, Lelan and Kapenguria. The disagreements were either related to ambiguous borders of property or when one clan assumed possession of land belonging to the other. During droughts, lack of livelihood sources and the quest for alternate sources prompted the impacted group members residing in lowlands to migrate to the highlands demanding possession of the conflict-causing arable property. Only after the dry spell did those disputes occur in the short term.

\subsection{Conclusion}

The study concludes that social economic factors were some of the reasons for persisted conflict among the pastoral communities of West Pokot and Turkana Counties in Kenya. Poverty and food deficits caused conflict, so raiding incidences naturally increased as people attempted to cope during lean periods brought about by droughts. It was established that the Pokot raid for territorial expansion, wealth creation and payment of bride price, while the Turkana raid due to drought and hunger. It was established that changes in cultural settings which had been caused by a multiple of factors affecting these pastoralists had contributed to the prolonged and continued conflict. Ethnography or cultural changes had led to destabilized community administrative structures. Therefore the study concluded that changes emanating from ecology, livelihoods, ethnography, raiding patterns, proliferation of small arms, governance, and peace building activities and political incitements from politicians from both communities were responsible for conflict between the two communities.

\subsection{Recommendations}

Based on the study findings, the current study recommends that the Government should take a more positive approach by involving proper, investigative policing when dealing with reports of cattle thefts. The government needs to respond urgently to pastoralist conflict replacing its reactive strategy with a more proactive one that seeks to equip its security forces, train and instill in them a sense of urgency and responsibility in handling incidents of pastoralist conflict. It is important to employ well-trained trackers to monitor stolen animals as far as possible, and frequent patrols should be carried out to search herds for suspect cattle. The police, moreover, must resist the urge to punish certain groups who they think are accountable. 


\section{References}

1. Abbink, J. (1997). Changing Patterns of Ethnic Violence": Peasant Pastoralist Confrontation in Southern Ethiopia and its implications for a Theory of Violence', Sociologus 44 (1), 66- 78

2. Akabwai, D., Ateyo, P. (2007). The scramble for Cattle, Power and Guns in Karamoja: Feinstein International Centre. Boston.

3. Azar, E., (1990). The management of protracted social conflict: Theory and cases. Dartmouth: Aldershot.

4. Behnke, R. (2008): The economic contribution of pastoralism: Case studies from the horn of Africa and Southern Africa. Nomadic peoples 12(1) 45-79.

5. Bollig, M. and Osterle, M. (2003): 'Communities and Discontinuities of Warfare in Pastoral Societies: Militarization and the Escalation of Violence', Zeitchrift for Entwicklungsecthnologie 12:109-43.

6. Bolllig, M. and Osterle, M. (2007): “We turned our enemies into baboons": warfare, rituals and pastoral identity among the Pokot of northern Kenya: Berghan Books, New York

7. CEWARN, 2010. CEWARN Country updates, September-December 2009. CEWARN (Conflict Early Warning and Response Mechanism): Addis Ababa.

8. Eaton, D. (2008): The rise of the 'traders': the commercialization of raiding in Karamoja Nomadic peoples 14(2): 106-122.

9. GOK, 2010. National Climate Change response strategy. Government Press: Nairobi.

10. Government of Kenya (2009). Population and Housing Census, Central Bureau for Statistics: Nairobi.

11. Gray, S., Sundal, M., Wiebusch, B., Little, M.A., Leslie, P.W., and Pike, I.L. (2003): 'Cattle Raiding, Cultural Survival, and Adaptability of East African Pastoralists'. Current Anthropology 44(suppl.) 53-530.

12. Greiner, C., (2013). Guns, Land, and Votes: Cattle Rustling and the Politics of boundary (Re) making in Northern Kenya: Oxford University Press (Nairobi).

13. Greiner, C., (2013). Guns, land, and votes: Cattle rustling and the politics of boundary (re) making in Northern Kenya. African Affairs, 112 (447), pp. 216-237.

14. Hendrickson, D., Armon, J., and Mearns, R. (1998): The changing nature of conflict and farming vulnerability: the case of livestock raiding in Turkana District, Kenya. Disasters 22(3): 185-199.

15. Juma, J. O., \& Simiyu, R. (2019). Nature and Causes of Inter-Ethnic Conflicts in Nyakach and Sigowet Sub-Counties of Western Kenya. Open Journal of Social Sciences, 7(7), 453-477.

16. Juma, J. O., Iteyo, C., \& Simiyu, R. (2018). The Nexus between Socio-Economic Environment and Recurrence of Inter-Ethnic Conflicts In Nyakach and Sigowet Sub-Counties of Western Kenya. The International Journal of Social Sciences and Humanities Invention, 5(4), 4595-4603.

17. Kenya Human Rights Commission (2010). Morans no more rustling in Kenya. Nairobi, Kenya Human Rights Commission

18. Mathew,S. and Robert, B., (2014). The cost of cowardice: Punitive sentiments towards free riders in Turkana raids. Evolution and Human Behavior, 35(1), pp. 58-64.

19. Mkutu and Wandera (2013): Small Arms Survey (2013). Policing the Periphery: Opportunities and Challenges for Kenya Police Reservists. Geneva.

20. Mkutu, K. (2000): Cattle Rustling and the Proliferation of Small Arms: the case of Baragoi, Samburu District. Paper presented at the conference 'Improving Human Security through the control and Management of Small Arms', Arusha, March 23-25. (Typescript)

21. Mkutu, K. (2006). Small arms and light weapons among pastoral groups in the Kenya-Uganda border area. African Affairs 106(422):47-70.

22. Mkutu, K. (2007a). Small arms and Light weapons among the pastoral groups in the Kenya-Uganda border regions. Crime, Law and Social Change, Vol. 38.

23. Mkutu, K. (2007b): Impact of small arms insecurity on the public health of pastoralists in the KenyaUganda border regions. In: Crime, Law and Social Change, Vol.47. 
24. Mkutu, K. (2008). Disarmament in Karamoja, Northern Uganda: Is this a solution for localized violent inter and intra-communal conflict? Round Table, 97 (394), pp. 99-120.

25. Murunga, G. R. and Shadrack W. N., (200). Kenya: The struggle for democracy. 1sted. New York, Zed Books Ltd

26. Mwaniki, T. W., Mbuchi, P. M., M., Leleruk and Mwei, F. (2007): Peace building and Conflict Management: Joint Case Study of North Rift Region of Kenya: Kolbe Press (Limuru).

27. Omari, E. (2011). "Named, Kenya's Richest and Poorest Counties. 'Daily Nation (Nairobi).17th December. http//www.nation/Named -Kenya's-richest and poorest-counties-/-/1056/1291292//item/2/-/gr3ldqz/-/indexhtml

28. Omolo, N. A. (2010). Gender and climate change- induced conflict in pastoral communities: case study of Turkana in northwestern Kenya. African Journal on Conflict Resolution.

29. Schilling, J., Opiyo, F.E. \& Scheffran, J. (2012). Raiding pastoral livelihoods: Motives and effects of violent conflict in north-western Kenya. Pastoralism 2: 25

30. UNEP/ GoK, (2000). Devastating droughts in Kenya: Environmental impacts and response. UNEP, Nairobi. 